\title{
EL MITO DE PROCUSTO Y LOS DESAFIOS DE LA INCLUSIÓN DE PERSONAS CON DEFICIENCIA EN LOS ESPACIOS UNIVERSITARIOS ${ }^{1}$
}

\author{
O MITO DE PROCUSTO E OS DESAFIOS DA INCLUSÃO DE \\ PESSOAS COM DEFICIÊNCIA NOS ESPAÇOS UNIVERSITÁRIOS
}

\section{THE MYTH OF PROSCRUSTES ANDTHE CHALLENGES OF INCLUSION OF DISABLED PEOPLE IN UNIVERSITY SPACES}

ROSÂNGELA ANGELIN

Pós-Doutora pela Faculdades EST, São Leopoldo-RS (Brasil). Doutora em Direito pela Universidade de Osnabrueck (Alemanha). Docente do Programa de PósGraduação stricto sensu - Mestrado e Doutorado em Direito da Universidade Regional integrada do Alto Uruguai e das Missões (URI), Campus Santo Ângelo/RS. Líder do Grupo de Pesquisa (CNPQ) Direitos de Minorias, Movimentos Sociais e Políticas Públicas. Coordenadora do Projeto de Pesquisa Direitos Humanos e Movimentos Sociais na Sociedade. E-mail: rosangelaangelin@yahoo.com.br

\section{LIANE MARLI SCHÄFER LUCCA}

Doutoranda e Mestre em Direito pelo Programa de Pós-Graduação stricto sensu Mestrado e Doutorado da Universidade Regional Integrada do Alto Uruguai e das Missões (URI), campus Santo Ângelo/RS. Integrante do Grupo de Pesquisa (CNPQ) Direitos de Minorias, Movimentos Sociais e Políticas Públicas e do Projeto de Pesquisa Direitos Humanos e Movimentos Sociais na sociedade multicultural. Bolsista da CAPES. E-mail: lialucca@san.uri.br

\footnotetext{
1 Esta investigación científica es financiada por CAPES (Coordenação de Aperfeiçoamento de Pessoal de Nível Superior), del gobierno brasileño.
} 


\section{RESUMEN}

Objetivo: La investigación busca reflexionar sobre el reconocimiento social y jurídico de personas con deficiencias para comprender cuales son los desafíos de la inclusión de estas personas en los ambientes universitarios.

Metodología: Desde un hipotético estudio deductivo, a través de una evolución doctrinal y legislativa de la literatura jurídica nacional y extranjera sobre el tema, pasando por la investigación de libros y artículos científicos de revistas especializadas.

Resultados: El estudio destaca que, aunque la legislación brasileña haya reconocido el acceso a las personas con deficiencia en los espacios académicos, su acogida por el cuerpo estudiantil y, en especial por el cuerpo docente, aún necesita ser perfeccionada a fin de que no se configure como una integración, lo que se compararía con el mito de Procusto.

Contribuciones: El tema de la inclusión ha sido objeto de gran repercusión en el ambiente educativo, en especial en la educación superior, debido a que las personas con deficiencia históricamente fueron relegadas a la enseñanza en escuelas especiales, atendiendo a la perspectiva hegemónica de segregación de todo lo que es diferente, negando, muchas veces, la posibilidad de inclusión de estas personas en la sociedad y, quizá en los espacios académicos.

Palabras claves: Personas con deficiencia; acceso a las universidades; inclusión.

\section{RESUMO}

Objetivo: A pesquisa busca refletir sobre o reconhecimento social e jurídico das pessoas com deficiências para compreender quais são os desafios da inclusão dessas pessoas nos ambientes universitários.

Metodologia: A partir de um estudo hipotético dedutivo, por meio de uma evolução doutrinal e legislativa da literatura jurídica nacional y estrangeira sobre o tema, mediante a pesquisa de obras e artigos científicos de revistas especializadas.

Resultados: $O$ estudo destaca que, muito embora a legislação brasileira tenha reconhecido o acesso às pessoas com deficiência nos espaços acadêmicos, sua acolhida pelo corpo discente e, em especial pelo corpo docente, ainda precisa ser qualificada, a fim de que a inclusão não se configure como uma integração, o que se coadunaria com o mito de Procusto.

Contribuições: O tema envolvendo a inclusão tem sido objeto de grande repercussão no ambiente educacional, em especial na educação superior, dado que 
as pessoas com deficiência historicamente foram relegadas ao ensino em escolas especiais, atendendo a perspectiva hegemônica de segregação de tudo e todos que são diferentes, afastando, por muitas vezes, a possibilidade de inclusão dessas pessoas no seio social e, quiçá nos bancos acadêmicos.

Palavras-chave: Pessoas com deficiência; acesso às universidades; inclusão.

\section{ABSTRACT}

Objective: This research seeks to reflect on the social and legal recognition of people with disabilities to understand which are the challenges for their inclusion in university environments.

Methodology: From a hypothetical deductive study, through a doctrinal and legislative evolution of the national and foreign legal literature on the subject, through the research of books and scientific articles from specialized journals.

Results: The study highlights that, although Brazilian legislation has recognized access to people with disabilities in academic spaces, their acceptance by the student body and, especially by the teaching staff, still needs to be qualified so that inclusion does not constitute an integration which would be in line with the myth of Procrustes.

Contributions: The subject concerning inclusion has been the object of great repercussion in the educational environment, especially in university education, given that people with disabilities have historically been relegated to education in special schools, given the hegemonic perspective of segregating everything and everyone that is different disregarding many times the possibility of including these people in social environments and, perhaps, even academic banks.

Keywords: Disabled people; access to universities; inclusion.

\section{INTRODUCCIÓN}

La mitología griega cuenta que en el camino a la ciudad de Atenas vivía o sádico Procusto. El ofrecía su hospitalidad atrayendo viajeros que pasaban por esa carretera. En su cabaña apenas había una cama de hierro. Procusto tenía la convicción de que la cama era la medida ideal de las personas. Entonces, intentaba seducirlas para que se acostaran en ella; si no lo conseguía, las obligaba con 
violencia. Si las piernas de algunas personas eran más largas que la cama, el las cortaba y si eran menores, las estiraba hasta alcanzar el tamaño que él consideraba que era el ideal.

La búsqueda por un patrón supuestamente ideal de seres humanos ha sido constante en la humanidad $y$, por consiguiente, ha generado muchos conflictos de orden individual y/o colectivo. Muchos holocaustos ya fueron realizados bajo esta justificativa e, en el de correr de los tiempos, las sociedades democráticas, de cuño humanista, se han esforzado para sobreponerse al síndrome de Procusto que permea los gobiernos, las leyes y la propia sociedad civil. En esa perspectiva basada en la dignidad, los derechos humanos han discurrido sobre la diversidad y su importancia en el contexto social de inclusión de todas las personas.

A pesar de las legislaciones que determinan la inclusión de personas con deficiencia en Brasil, acciones efectivas en pro de esta necesidad encuentran barreras constantes de aceptación, aplicabilidad y reconocimiento. Entre el texto da la ley y la ejecución de sus directrices, hay una distancia considerable de dificultades. Siendo así, la investigación busca reflexionar sobre el reconocimiento social y jurídico de las personas con deficiencias para comprender cuales son las limitaciones y los avances de la inclusión de esas personas en los ambientes universitarios

Para desenvolver el objetivo propuesto anteriormente, por medio de un estudio hipotético deductivo, primero serán contextualizados aspectos teóricos sobre identidad, diferencia y alteridad, relacionándolos en la perspectiva de las personas con deficiencia. Luego, se busca enumerar las principales conquistas jurídicas con relación al acceso de personas con deficiencia em espacios educativos, para finalmente, reflexionar sobre los desafíos de las Universidades en los procesos de inclusión de personas con deficiencia. 


\section{APORTES TEÓRICOS ACERCA DE IDENTIDAD, DIFERENCIA Y ALTERIDAD EN LA PERSPECTIVA DEL RECONOCIMIENTO DE PERSONAS CON DEFICIENCIA}

En la música, Ser diferente es normal, que compone el repertorio del cantor brasileño Lenine, la diferencia aparece como una característica singular e importante que dialoga con las identidades y la diversidad humana. Es justamente en las diferencias que la normalidad se debe encontrar, pues, ser diferente es normal. Por más que esa perspectiva sea constante en los discursos políticamente correctos, las diferencias han sido comprendidas, principalmente, como características negativas que confrontan patrones y estereotipos de identidad entendidos como normales en las personas con deficiencia, haciendo con que situaciones sociales cotidianas confronten, inclusive, los posicionamientos jurídicos más humanizados.

Cada ser humano posee su identidad. Las identidades pueden ser caracterizadas como aquello que constituye el ser de cada persona, destacándose el origen del lugar de donde proceden; de aquello que traen como los lazos familiares construidos a través de costumbres y valores; de las opiniones que forman, así como también de las relaciones que establecen con las personas con quienes conviven. Una identidad está compuesta por reacciones a las otras identidades, lo que acaba por generar la búsqueda de una identidad construida a partir de otras, siendo esta solo destruida por el simple hecho del reconocimiento de las demás identidades (TAYLOR, 1994).

Identidades pueden ser consideradas como todo lo que ayuda a la formación social y moral de un individuo que vive en sociedad. En el contexto social se encuentran identidades que se pareen entre sí y otras que se distinguen; aun siendo distintas, pueden expresar ciertas semejanzas, pues dependen de las otras para identificarse y construirse. Entonces, el proceso por el cual las identidades pasan para su construcción se parece también con su identificación ante los otros, sea por semejanzas o por diferencias culturales, étnicas, económicas e de género, entre otras. Todas esas cuestiones proporcionan formatos a las identidades, posibilitando la opción de escoger entre las varias identidades y la definición de cuáles serían 
incluidas y/o excluidas en la forma de ser del individuo (WOODWARD, 2013). En la concepción de Stuart Hall (2013) las identidades son formadas no solamente por procesos producto de las reacciones, también son construcciones que ocurren de manera inconsciente. De esa forma, las identidades siempre están incompletas y en proceso de (re)construcción, influenciadas por el exterior y siendo perfeccionadas, inclusive, a partir de como las personas imaginan ser vistas por otros y otras. En realidad, es necesario considerar con más atención el hecho de que las identidades necesitan del contraste para ser construidas, o sea, necesitan de la diferencia para poder afirmarse como propias. Su construcción ocurre por medio de la interrelación social, que genera el reconocimiento social, pudiendo ser un reconocimiento correcto o, hasta igualmente, equivocado de identidades (TAYLOR, 1994).

En esta medida, es posible afirmar que no existen identidades sin que haya diferencias. La diferencia puede ser construida negativamente por medio de la exclusión o de la marginalización de aquellas personas definidas como las otras, pues no se encuadran en las categorías de identidad hegemónica. Por otro lado, ella puede ser celebrada como fuente de diversidad, heterogeneidad y mezcla, lo que la hace ver como enriquecedora. Siendo así, las identidades son fundamentadas en las diferencias. Una identidad depende de las circunstancias y características de otras identidades para poder existir; depende de la diferencia para que se pueda tornar identidad y establezca sus particularidades frente al otro (WOODWARD, 2013).

Tomaz Tadeu da Silva llama la atención para las relaciones de poder en las disputas de identidad, que también ocurre en torno de las personas con deficiencia, las cuales cargan estigmas y preconceptos por ser diferentes de patrones de identidad considerados como normales. $Y$ es en esa diferenciación que surge el proceso de inclusión o de exclusión, de clasificación y determinación de quien es normal o no. Por lo tanto, la vida en sociedad acaba siendo dividida entre el que se considera como nosotros, y ellos, o sea, los otros, diferentes de nosotros (SILVA, 2013). Esa clasificación - nosotros y ellos, se encuentra fundamentada en un pensamiento binario y dualista basado en una estructura mental logo céntrica que busca estructurar verdades absolutas y totalmente distintas, confundiendo la comprensión de que los seres humanos, aunque diferentes, comparten cosas 
específicas y singulares que los aproximan en relación con la existencia humana (HAHN; ANGELIN, 2015). Tanto las identidades como las diferencias, son categorías de la vida social, construidas a partir de ideologías, relaciones de poder, espacios sociales temporales y tienden a universalizar e influenciar en la convivencia social, dando como resultado la inclusión o la exclusión a partir de categorías binarias como afirmado anteriormente.

Es importante tener presente que, desde el punto de vista sociológico, las identidades son construcciones cotidianas, que envuelven intereses que son delimitados por factores históricos, biológicos, religiosos, sociales, económicos, mas también, de aspectos que envuelven la memoria colectiva (CASTELS, 2010), lo que remite a entender que no existe rigidez de identidad; por tanto, esas son plausibles de cambios y modificaciones en su reconocimiento social.

Simultáneamente, tanto la identidad como la diferencia son elementos inseparables y construidos, conjuntamente, dentro de una determinada cultura, incluyendo la convivencia: "La identidad no se refiere apenas al mundo, mas también a la forma como vive el ser humano en su manera de pensar y de manipular su mundo histórico y, también, la a forma como él construye su proyección introspectiva y estética del mundo" (SIDEKUN, 2003, p. 266). ${ }^{2}$ Observando las personas con deficiencia, Luis Alberto Warat, concuerda con esa perspectiva de análisis sobre el lugar de los cuerpos y de las identidades en la sociedad, cuando afirma que, "La sociedad y sus condiciones imponen la censura a los cuerpos que sienten. Son las ideas que determinan las condiciones para que los otros nos amen, sean indiferentes o nos tengan odio" (WARAT, 2004, p. 28). ${ }^{3} \mathrm{~A}$ la vez, estas condiciones rodeadas deuna racionalidad ausente de sentimientos de alteridad, alejan las personas del reconocimiento reciproco ante la sociedad y, más aún, son reproductoras de preconceptos, cultura de odio y exclusión social. La alteridad viene

\footnotetext{
2 Traducción de las autoras del artículo. En el idioma original: "A identidade não faz referência apenas ao mundo, porém à forma como vive o ser humano na sua maneira de idear e de manipular o seu mundo histórico e, também, o modo como ele constrói sua projeção introspectiva e estética do mundo."

${ }^{3}$ Traducción de las autoras del artículo. En el idioma original: "A sociedade e suas condições impõem a censura aos corpos que sentem. São as idéias que determinam as condições para que os outros nos amem, sejam indiferentes ou nos tenham ódio."
} 
a ser um proceso ético de reconocimiento del otro por medio de la sensibilidad de ver, sentir, colocarse al lado de ese otro. Solo así se puede reflexionar a partir de sus vivencias, sus historias, su lugar en la sociedad.

La emancipación de las personas sobrepasa a un conjunto de experiencias radicales de alteridad, relacionadas al establecimiento de vínculos fundamentados en el cuidado y el afecto. Además, "puede ser la posibilidad de preservar el espacio interior propio, secreto, inaccesible. La intimidad del yo que funcione como límite y condición de la autonomía. Es necesario construir nuestra alteridad con extrema selectividad y esa selectividad se puede llamar de emancipación" (MALEUS; THAINES, 2015, p. 211). Ese entendimiento permite una reflexión paradójica en el caso de las personas con ciertos tipos de deficiencias, en el sentido de que, aun en los casos donde algunas de sus capacidades sean limitadas, ellas pueden y necesitan tener espacios de desenvolvimiento de su autonomía para que alcancen niveles de emancipación, respetando el límite de sus diferencias. Esa manera de percibir a las personas con deficiencia en la sociedad, va en contra de las medidas de la cama de Procusto, así como también, de la visión dualista o binaria de inclusión y exclusión, forzando a la sociedad a buscar otra forma de verlos, otra forma de relacionarse con estas personas y, al mismo tiempo, incluirlas en el contexto social. Con este propósito Luis Alberto Warat (1996) denuncia la racionalidad centrada binaria e hegemónica que acaba por cerrar las categorías del pensamiento humano, impidiendo ver al otro con sus diferencias. El autor lanza el desafío para la sociedad de salir de la zona de comodidad y ver al otro a partir de distintos parámetros, con otras lentes y con sensibilidad capaz de generar humanización, sin estar preso a reglas unificadoras de significados:

La celebración del pensamiento: lo impensado que nos fuerza a pensar, que llama a lo nuevo, renegando todo y cualquier tipo de ambición unificadora de los significados. De ninguna manera síntomas de impotencia del pensamiento: es más bien lo que fortalece, lo que obliga al pensador, con la fuerza de una pasión, a plantearse problemas y no a dar soluciones. Un

\footnotetext{
${ }^{4}$ Traducción de las autoras del artículo. En el idioma original: "pode ser a possibilidade de preservar o espaço interior próprio, secreto, inacessível. A intimidade do eu que funcione como limite e condição da autonomia. É preciso construir nossa alteridade com extrema seletividade e essa seletividade pode-se chamar de emancipação."
} 
pensamiento que intenta que el hombre pueda volverse digno de lo que sucede, de lo impensable, del azar: una ética del pensamiento (WARAT, 1996, p. 74-75). ${ }^{5}$

En su obra A Rua Grita Dionísio! Direitos humanos da alteridade, surrealismo e cartografia, (La Calle grita Dionísio! Derechos Humanos de la alteridad, surrealismo y cartografía), Warat (2010) denuncia la acción del Proyecto ideológico de globalización neoliberal que procura uniformizar todo a su alrededor, inclusive a las personas, destruyendo, excluyendo y/o invisibilizado las diferencias, en especial, aquellas que no están aptas para atender las reglas del capital, incluyéndose aquí, una gran cantidad de personas con deficiencia. En contraste y, de acuerdo con lo que ya se mencionó antes, el autor sugiere la creación de un espacio de resistencia, que denomina de entre-nosotros, espacio este de dialogo, destaque y respeto a las diferencias, buscando puntos de encuentro entre estas. Este espacio debería ser ocupado por teorías del conocimiento responsables, capaces de dialogar con las realidades a su alrededor.

La búsqueda de Warat por sentimientos sensibles de alteridad permea sus obras que, de acuerdo con Oliveira Junior (2014), están repletas de gritos orientados para los derechos humanos, para la solidaridad entre las personas, y además muestran la necesidad de más afectos y amores en las relaciones entre las personas. Es en esta perspectiva que la siguiente sección abordará el reconocimiento jurídico de las personas con deficiencia en Brasil.

\section{NORMATIVAS DE INCLUSIÓN DE PERSONAS CON DISCAPACIDAD EN LOS ESPACIOS EDUCATIVOS}

Las personas con deficiencia históricamente fueron relegadas a un plano

\footnotetext{
5 Traducción de las autoras del artículo: “A celebração do pensamento: o impensável que nos obriga a pensar, que chama ao novo, negando tudo e qualquer tipo de ambição unificadora dos significados. De maneira alguma são sintomas de impotência de pensamento: é antes esse poder, que força o pensador, com a força de uma paixão, a colocar problemas e não dar soluções. Um pensamento que tenta que o homem possa se tornar digno do que acontece, do impensável, do acaso: uma ética do pensamento" (WARAT, 1996, p. 74-75).
} 
inferior, sin tener la debida protección de la justicia social, que otrora los veía como parias, pues eran mantenidos al margen de la sociedad, excluidos de la convivencia social, conforme afirman Forhmann y Angélica:

\begin{abstract}
Ao longo da história, o tratamento dispensado pela sociedade às pessoas com deficiência passou por momentos de extrema intolerância e discriminação, resultando, em muitos casos, na marginalização desses indivíduos. Embora tenhamos avançado no tema, ainda hoje, grande parte das pessoas com deficiência encontra uma série de barreiras que dificultam $\mathrm{e}$, às vezes, impedem o pleno exercício de direitos garantidos a todos os cidadãos, como é o caso dos direitos à saúde, à educação, ao trabalho e ao transporte. Tal prática contribui para gerar uma relação de desigualdade (FOHRMANN; ANGÉLICA, 2014, p. 9). ${ }^{6}$
\end{abstract}

La exclusión de las personas con deficiencia ocurría en las más diversas esferas, inclusive la educativa, donde estas personas eran relegadas a clases especiales, o aun, a espacios escolares especiales. En este formato educativo, estas personas dejaban de interactuar con la comunidad escolar, requisito de fundamental importancia para la integración, aceptación y convivencia en el medio social, así como para el ejercicio de los derechos más básicos, propios de la ciudadanía. Los debates en torno al acceso a la educación de personas con deficiencia enfrentan una perspectiva que puede ser dudosa, partiendo de como es encaminada, o sea, puede asumir modelos integracionistas o de inclusión. La visión integracionista defiende que las personas con deficiencia deben adecuarse al status quo del ambiente que comienzan a frecuentar, ya que la visión de inclusión apunta a lo contrario, según afirman Fohrmann y Angélica:

Nesse sentido, a "inclusão" funciona de maneira diretamente oposta à
"integração", já que não defende a necessidade de adaptação das pessoas
com deficiência ao meio social, mas prevê que o próprio meio social se
adapte a essas pessoas, através da adoção de políticas públicas positivas
que atuem a fim de evitar a exclusão e reduzir as desigualdades. Para
aqueles que defendem a "inclusão", o ensino fundamental deve ocorrer em

6 Traducción de las autoras del artículo: "A lo largo de la historia, el tratamiento provisto por la sociedad a las personas con deficiencia pasó por momentos de extrema intolerancia y discriminación, resultando, en muchos casos, en la marginación de estos individuos. Aunque hayamos avanzado en el tema, aún hoy, gran parte de las personas con deficiencia encuentran una serie de barreras que dificultan y, a veces, impiden el pleno ejercicio de derechos garantizados a todos los ciudadanos, como es el caso del derecho a la salud, a la educación, al trabajo y al transporte. Tal práctica contribuye para generar una relación de desigualdad" (FOHRMANN; ANGÉLICA, 2014, p. 9). 
classes regulares nas escolas comuns, conferindo às pessoas com deficiência o mesmo direito atribuído aos demais indivíduos (FOHRMANN; ANGÉLICA, 2014, p. 20). ${ }^{7}$

La cuestión de la educación inclusiva en Brasil, para las personas con deficiencia, encuentra fundamento legal en diversas autorizaciones normativas que rigen las políticas públicas. El compromiso firmado por ocasión de las diversas convenciones internacionales dio como resultado las Reglas Generales de Igualdad de Oportunidades para Personas con Deficiencias, divulgadas en la Declaración de Salamanca, procedente de la Conferencia Mundial en Educación Especial organizada por el gobierno de España en cooperación con la UNESCO, realizada en Salamanca del 7 al 10 de junio de 1994, que tiene como objetivo central, lo siguiente:

\begin{abstract}
Informar sobre políticas e guias ações governamentais, de organizações internacionais ou agências nacionais de auxílio, organizações nãogovernamentais e outras instituições na implementação da Declaração de Salamanca sobre princípios, Política e prática em Educação Especial. A Estrutura de Ação baseia-se fortemente na experiência dos países participantes e também nas resoluções, recomendações e publicações do sistema das Nações Unidas e outras organizações inter-governamentais, especialmente o documento "Procedimentos-Padrões na Equalização de Oportunidades para pessoas Portadoras de Deficiência". Tal Estrutura de Ação também leva em consideração as propostas, direções e recomendações originadas dos cinco seminários regionais preparatórios da Conferência Mundial (DECLARACIÓN DE SALAMANCA, 1994, s.p.). ${ }^{8}$
\end{abstract}

\footnotetext{
7 Traducción de las autoras del artículo: "En ese sentido, la 'inclusión' funciona de manera directamente opuesta a la 'integración' ya que no defiende la necesidad de adaptación de las personas con deficiencia al medio social, pero prevé que el propio medio social se adapte a estas personas, a través de la adopción de políticas públicas positivas que actúen a fin de evitar la exclusión y reducir las desigualdades. Para aquellos que defienden la 'inclusión', la enseñanza fundamental debe ocurrir en clases regulares en las escuelas comunes, dando a las personas con deficiencia el mismo derecho dado a los demás individuos" (FOHRMANN; ANGÉLICA, 2014, p. 20).

8 Traducción de las autoras del artículo: "Informar sobre políticas y guías de acciones gubernamentales, de organizaciones internacionales o agencias de auxilio, organizaciones no gubernamentales y otras instituciones en la implementación de la Declaración de Salamanca sobre principios, Política y Práctica en Educación Especial. La estructura de Acción se basa fuertemente en la experiencia de los países participantes y también en las resoluciones, recomendaciones y publicaciones del sistema de las Naciones Unidas y otras organizaciones intergubernamentales, especialmente el documento 'Procedimientos bases para la igualdad de oportunidades de personas portadoras de deficiencia'. Tal estructura de acción también considera las propuestas, direcciones y recomendaciones de los cinco seminarios regionales preparatorios de la Conferencia Mundial" (DECLARAÇÃO DE SALAMANCA, 1994, s.p).
} 
Además, el tema en estudio también abarca el Decreto oㅜ 6.949, del 25 de agosto de 2009, que incluye en el ordenamiento patrio la Convención Internacional sobre los derechos de las personas con Deficiencia y su Protocolo Facultativo, firmados en Nova York, el 30 de marzo de 2007 (BRASIL, 2009). En este contexto, se desenvolvió la Política Nacional de Educación Especial, en la perspectiva de la Educación Inclusiva elaborada por el Grupo de Trabajo, la cual instituyó considerables reformulaciones en la enseñanza fundamental, media y superior, convirtiéndose en una referencia importante en relación a la educación especial e inclusión en nuestro país. La política pública presentada por este documento pasó a atender la demanda de la educación especial sobre una nueva óptica, buscando minar la noción de escuela concebida en el pasado, en la que predominaba el privilegio de pocos y la exclusión de muchos. Así la cuestión de la inclusión en espacios educativos está amparada en múltiples legislaciones. En este momento histórico, los centro educativos, sobre la perspectiva pedagógica, deben estar atentos al cumplimiento de lo dispuesto en cuatro ordenamientos distintos que tratan sobre el tema, los cuales son:

Lei $n^{\circ} 10.098$, de 19 de dezembro de 2000, que estabelece normas gerais e critérios básicos para a promoção da acessibilidade das pessoas portadoras de deficiência ou com mobilidade reduzida, e dá outras providências, regulada pelo Decreto-lei 5296, de 2 de dezembro de 2004. Regulamenta a Lei $n^{\circ} 10.048$, de 8 de novembro de 2000, que dá prioridade de atendimento às pessoas com deficiência, e a Lei $n^{\circ} 10.098$, de 19 de dezembro de 2000, que estabelece normas gerais e critérios básicos para a promoção da acessibilidade (BRASIL, 2000).

Lei no 10.436, de 24 de abril de 2002, que dispõe sobre a Língua Brasileira de Sinais - LIBRAS e dá outras providências, regulada pelo Decreto $n^{\circ}$ 5.626, de 22 de dezembro de 2005. Regulamenta a Lei $n^{\circ} 10.436$, de 24 de abril de 2002, que dispõe sobre a Língua Brasileira de Sinais - Libras, e o art. 18 da Lei $n^{\circ}$ 10.098, de 19 de dezembro de 2000 (BRASIL, 2002).

Lei no 12.764, de 27 de dezembro de 2012, que institui a Política Nacional de Proteção dos Direitos da Pessoa com Transtorno do Espectro Autista e altera $\circ \S 30$ do art. 98 da Lei $n^{\circ} 8.112$, de 11 de dezembro de 1990. Regulamenta a Lei $\mathrm{n}^{0}$ 12.764, de 27 de dezembro de 2012, que institui a Política Nacional de Proteção dos Direitos da Pessoa com Transtorno do Espectro Autista (BRASIL, 2012). 
Lei no 13.146, de 6 de julho de 2015, que Institui a Lei Brasileira de Inclusão da Pessoa com Deficiência (BRASIL, 2015). ${ }^{9}$

Las legislaciones expuestas anteriormente expresan que el acto de incluir personas con deficiencias en espacios de educación formal exige, mínimamente, el conocimiento y entendimiento de una gran cantidad de documentos legales cuyo objetivo es asegurar y consolidar los derechos de la persona con deficiencia. Se observa que la cuestión de la promoción de accesibilidad de personas con deficiencia, o con movilidad reducida, encuentra sus bases de acción en la Ley 10.098/2000, con su objetivo fundamentado en el art. 1ํㅜ que anuncia que esa legislación busca establecer

[...] normas gerais e critérios básicos para a promoção da acessibilidade das pessoas portadoras de deficiência ou com mobilidade reduzida, mediante a supressão de barreiras e de obstáculos nas vias e espaços públicos, no mobiliário urbano, na construção e reforma de edifícios e nos meios de transporte e de comunicação (BRASIL 2000). ${ }^{10}$

Frente a la diversidad de tipos de deficiencias, están las personas portadoras de deficiencia auditiva, amparadas por la Ley 10.436/2002, que contempla la LIBRAS - Lengua Brasileira de Señales. Ese es el segundo idioma

\footnotetext{
9 Traducción de las autoras del artículo: "Ley $n^{\circ}$ 10.098, del 19 de diciembre de 2000, que establece normas generales y criterios básicos para la promoción de la accesibilidad de las personas portadoras de deficiencia o con movilidad reducida, y da otros poderes providenciales, regulada por el Decretoley 5296, de 2 de diciembre de 2004. Reglamenta la Ley $n^{\circ} 0.048$, del 8 de noviembre de 2000, que da prioridad de atendimiento a las personas con deficiencia, e la Ley oㅜ 10.098 de diciembre de 2000, que establece normas generales y criterios básicos para la promoción de la accesibilidad (BRASIL, 2000). Ley no 10.436, del 24 de abril de 2002, que dispone sobre la Lengua Brasilera de Señales LIBRAS y dá otras sentencias, regulada por el Decreto № 5.626 del 22 de diciembre de 2005. Reglamenta la Ley no 10436 del 24 de abril de 2002, que dispone sobre la Lengua Brasilera de Señales - Libras, y el art. 18 de la Ley no 10.098 del 19 de diciembre de 2000 (BRASIL, 2002). Ley no 12.764, del 27 de diciembre de 2012, que instituye la Política Nacional de Protección de los Derechos de las Personas con Trastorno del Espectro Autista y altera el $\S 3$ del art. 98 de la Ley no 8.112, del 11 de diciembre de 1990. Reglamenta la Ley 운.764 del 27 de diciembre de 2012, que instituye la Política Nacional de Protección de los Derechos de las Personas con Trastorno del Espectro Autista (BRASIL, 2012). Ley no 13.146, del 6 de julio de 2015, que instituye la Ley Brasileña de Inclusión de la persona con Deficiencia (BRASIL, 2015)."

10 Traducción de las autoras del artículo: "normas generales y criterios básicos para la promoción de la accesibilidad de las personas portadoras de deficiencia o con movilidad reducida, mediante la suspensión de barreras y de obstáculos en las vías y espacios públicos, en la movilidad urbana, en la construcción y reforma de edificios y los medios de transporte y de comunicación" (BRASIL, 2000).
} 
oficial de Brasil, que no suprime la modalidad escrita de la lengua portuguesa. El parágrafo único del art. 1으, del mencionado documento legal, define lo que es la LIBRAS:

Língua Brasileira de Sinais - Libras a forma de comunicação e expressão, em que o sistema linguístico de natureza visual-motora, com estrutura gramatical própria, constitui um sistema linguístico de transmissão de ideias e fatos, oriundos de comunidades de pessoas surdas do Brasil (BRASIL, 2002). ${ }^{11}$

En lo que se refiere a las personas con autismo, en 2012, fue promulgada la Ley 12.764 la cual ampara cuestiones relacionadas con la protección de los Derechos de la Persona con Trastorno del Espectro Autista. O art. $1^{\circ}$ en su parágrafo primero e incisos, define lo que es el autismo:

\begin{abstract}
É considerada pessoa com transtorno do espectro autista aquela portadora de síndrome clínica caracterizada na forma dos seguintes incisos I ou II: I deficiência persistente e clinicamente significativa da comunicação e da interação sociais, manifestada por deficiência marcada de comunicação verbal e não verbal usada para interação social; ausência de reciprocidade social; falência em desenvolver e manter relações apropriadas ao seu nível de desenvolvimento; II - padrões restritivos e repetitivos de comportamentos, interesses e atividades, manifestados por comportamentos motores ou verbais estereotipados ou por comportamentos sensoriais incomuns; excessiva aderência a rotinas e padrões de comportamento ritualizados; interesses restritos e fixos (BRASIL, 2012). ${ }^{12}$
\end{abstract}

En 2015 fue promulgada la ley 13.146, ampliamente conocida como el Estatuto de la Persona con Deficiencia, el cual dispone, en su art. 27, sobre el acceso a la educación, y que declara:

11 Traducción de las autoras del artículo: "Lengua Brasileña de Señales - Libras la forma de comunicación y expresión, en que el sistema lingüístico de naturaleza visual-motora, con estructura gramatical propia, constituyen un sistema lingüístico de trasmisión de ideas y hechos, originarios de comunidades de personas sordas de Brasil" (BRASIL, 2002).

12 Traducción de las autoras del artículo: "Es considerada persona con trastorno del espectro aquella portadora de síndrome clínico caracterizada según los siguientes incisos I o II: I deficiencia persistente y clínicamente significativa de la comunicación y de la interacción social, manifestada por deficiencia marcada de comunicación verbal y no verbal usada para interacción social; ausencia de reciprocidad social; falla en desenvolver y mantener relaciones apropiadas a su nivel de desarrollo. IImodelos restrictivos y repetitivos de comportamientos, intereses y actividades, manifestados por comportamientos motores o verbales estereotipados o por comportamientos sensoriales inusuales, apego a rutinas excesivamente rígidas y patrones de comportamiento ritualizado; intereses limitados y fijos" (BRASIL, 2012). 
Art. 27. A educação constitui direito da pessoa com deficiência, assegurado sistema educacional inclusivo em todos os níveis e aprendizado ao longo de toda a vida, de forma a alcançar o máximo desenvolvimento possível de seus talentos e habilidades físicas, sensoriais, intelectuais e sociais, segundo suas características, interesses e necessidades de aprendizagem. Parágrafo único. É dever do Estado, da família, da comunidade escolar e da sociedade assegurar educação de qualidade à pessoa com deficiência, colocando-a a salvo de toda forma de violência, negligência e discriminação (BRAASIL, 2015). ${ }^{13}$

En este amplio contexto legislativo, las Instituciones de Enseñanza Superior están enfrentando desafíos que otrora no les correspondían, dado de que las personas con deficiencia difícilmente conseguían alcanzar tal nivel de enseñanza, considerando las históricas barreras de acceso a la enseñanza superior, así como las cuestiones ligadas a la forma totalmente separada como eran educados, relegados a un modelo que propagaba segregación y aislamiento. Por tanto, frente a estas normativas el Estado y otras instituciones son responsabilizados para la realización de una efectiva inclusión. Siendo así, la próxima sección abordará el principio de la responsabilidad frente a la inclusión de personas con deficiencia en espacios universitarios, revelando desafíos referentes a esa temática.

\section{APARTANDO LAS PERSONAS CON DEFICIENCIA DE LA CAMA DE PROCUSTO: DESAFÍOS UNIVERSITARIOS PARA LA INCLUSIÓN}

La educación, tanto formal, cuanto informal, acontece en los espacios de la diversidad de las relaciones humanas, haciendo con que el resultado de esas relaciones sea una responsabilidad de toda la sociedad. Indudablemente, ese es un proceso bastante complicado, que trae innumerables dudas en relación a la forma de promoción de la educación inclusiva y, al mismo tiempo, al atendimiento del deber

\footnotetext{
13 Traducción de las autoras del artículo: "Art. 27. La educación constituye un derecho de la persona con deficiencia, asegurando sistema educacional inclusivo en todos los niveles y aprendizaje a lo largo de toda la vida, de forma a alcanzar el máximo desarrollo posible de sus talentos y habilidades físicas, sensoriales, intelectuales y sociales, según sus características, intereses y necesidades de aprendizaje. Parágrafo único. Es deber del Estado, de la familia, de la comunidad escolar y de la sociedad asegurar educación de calidad a la persona con deficiencia, colocándola a salvo de toda forma de violencia, negligencia y discriminación" (BRASIL, 2015).
} 
legal de igualdad, sin reprimir las diferencias, especialmente en el medio universitario, no sometiendo a las personas a la cama de Procusto. Frente al papel de la educación en las relaciones humanas, Carbonari reflexiona sobre la complejidad enfrentada en los espacios académicos:

A educação ocorre na concretude da relação, que é constitutiva da vida, ou não ocorre. Não há vida (e nem educação) sem relação, sem alteridade. Mas o outro da relação não é um outro generalizado nem abstrato [...]. O outro da relação é diverso e diferente, sua diversidade é específica e sua diferença concreta (CARBONARI, 2011, p. 122). ${ }^{14}$

En el contexto del reconocimiento e inclusión de los más diversos grupos sociales, objeto de acalorados debates en el área del derecho, el objetivo son las personas con deficiencia que en la esfera educativa antes fueron destinados a la segregación, especialmente en las escuelas y universidades. Lo que de hecho se demuestra en las pocas noticias de personas con deficiencia que tengan acceso y disfruten de enseñanzas privilegiadas para un selecto grupo de ciudadanos que llega a la enseñanza superior. En el contexto de transformaciones principalmente a nivel internacional y, frente a los acuerdos sobre el respeto a las diferencias, se destaca el impacto de éstas en la reestructuración de la educación en la esfera nacional, imponiendo la ejecución de políticas públicas de inclusión, con el propósito de permitir a este nuevo público, acceso a una educación superior de calidad, sin preconceptos, e efectivamente inclusiva.

En la historia educativa brasileña, fueron pocas las personas con deficiencia que llegaron a los asientos universitarios. Por eso, esa forma de inclusión trae consigo una variedad de consecuencias para las personas involucradas, estableciendo la necesidad de cambios de posicionamientos frente a un status quo que ya no es adecuado para esta nueva perspectiva. Se concluye que, ajustarse a lo que antes se tenía como algo homogéneo y arraigado en la práctica antigua para

\footnotetext{
14 Traducción de las autoras del artículo: "La educación acontece precisamente en la relación, que es constitutiva de la vida, o no acontece. No hay vida (ni educación) sin relación, sin alteridad. Pero el otro de la relación no es otro generalizado ni abstracto [...]. El otro de la relación es diverso y diferente, su diversidad es específica y su diferencia concreta" (CARBONARI, 2011, p. 122).
} 
una perspectiva más diversa, significa un largo proceso de adaptación e reformulación de antiguos conceptos y posicionamientos.

A partir de la percepción introducida en los medios académicos, considerando los derechos humanos y el papel del sujeto como instrumento de mitigación de la contradicción de la inclusión, se presenta la cuestión de la universalización del acceso a la educación. Esta nueva visión deja atrás la perspectiva de la enseñanza homogénea e inicia una perspectiva heterogénea enfocada en las necesidades y percepciones de los individuos, a fin de proporcionar una educación no solo inclusiva, sino también participativa. La inclusión contempla mucho más que el mero interés legal en hacer efectiva una $u$ otra política. Considerando la perspectiva educativa, ella busca incentivar la participación de toda la estructura de la educación formal, orientadas para una convivencia ciudadana elaborada desde un espacio capaz de acoger personas con o sin deficiencias (MANICA; CALIMAN, 2015).

Felicity Armstrong hace referencia a la profunda transformación concebida en la comunidad educativa frente a la perspectiva de inclusión de estudiantes, haciendo distinción entre los integrables y los integrados.

\begin{abstract}
A integração escolar é uma medida parcial, uma simples melhoria do especial. De um lado, distinguem-se os alunos "integráveis" e aqueles que não o são. Do outro, os "integrados" mantêm o status de meros "visitantes" quando estão no meio escolar usual. $A$ inclusão e a educação inclusiva, ao contrário, repousam em uma posição radical que implica a presença de todas as crianças em um tronco comum, como membros plenos da comunidade escolar. Ao mesmo tempo, isso demanda uma transformação das escolas e das práticas profissionais, ou seja, não mais a adaptação das crianças a dependências educativas permanentes, mas, ao contrário, a adaptação dessas dependências às diferenças acolhidas (ARMSTRONG apud PLAISANCE, 2015, p. 236). ${ }^{15}$
\end{abstract}

15 Traducción de las autoras del artículo: "La integración escolar es una medida parcial, una simple mejoría de lo especial. Por un lado, se distinguen los alumnos 'integrables' y aquellos que no lo son. Por otro lado, los integrados mantienen el status de simples 'visitantes' cuando están en el medio escolar común. La inclusión y la educación inclusiva, al contrario, descansan en una posición radical que implica la presencia de todos los niños en un grupo común, como miembros plenos de la comunidad escolar. Al mismo tiempo, esto demanda una transformación de las escuelas y de las prácticas profesionales, o sea, estudiantes no se adaptan a las dependencias educativas existentes, sino que, al contrario, las dependencias se adaptan a las diferencias de estudiantes" (ARMSTRONG apud PLAISANCE, 2015, p. 236). 
El proceso de inclusión presenta diversos aspectos y, en esa coyuntura, está el panorama de los docentes directamente involucrados con los sujetos y, especialmente desafiados a reformular su forma de enseñar, adicionando al asunto de la enseñanza la heterogeneidad de sus estudiantes. Para una efectiva inclusión de personas con deficiencia en los espacios universitarios son necesarios algunos aspectos que abarcan desde el respeto a las diferencias hasta la adaptación curricular y la preparación de los docentes, según la reflexión de Lopes:

\begin{abstract}
O processo de inclusão pressupõe que as diferenças tenham espaço dentro do currículo escolar, que as diversas vozes possam dizer de si. Todavia, os processos e inclusão fomentados no país falam de adaptações curriculares de formação rápida de docentes (quando existem). Diante de tanta pressão para a inclusão, os professores sentem-se pressionados e desencorajados a dizer que não sabem desencadear tal processo. Ao mostrarem-se receosos à inclusão, os professores deixam explícitos não só a falta de condição que estão vivendo nas escolas para que esse processo aconteça, como também o despreparo para tal trabalho. [...] Precisamos saber sobre aqueles os quais trabalhamos. Saberes que vão além da minha leitura sobre as condições de vida dos meus alunos, ou seja, preciso de saberes que me possibilitem trabalhar desencadeando processos de aprendizagens. Para tanto, o saber sobre como os sujeitos aprendem, sobre como conceituo conhecimento, sobre como os sujeitos surdos se comunicam e sobre a própria Língua Brasileira de Sinais, sobre as especificidades de trabalhar com pessoas que possuem diferentes deficiências [...] é fundamental e condição mínima de trabalho (LOPES, 2007, p. 27-28). ${ }^{16}$
\end{abstract}

Las universidades se deparan, por tanto, con diferentes realidades íntimamente relacionadas a un fin común, o sea, asociadas a la promoción de la inclusión y para enfrentar responsabilidades propias del deber legal, propuestas por las políticas públicas de inclusión. Flores $(2009$, p. 32) señala que "problematizar la

16 Traducción de las autoras del artículo: "El proceso de inclusión presupone que las diferencias tengan espacio dentro del currículo escolar, que las diversas voces puedan decir de sí. Es más, los procesos e inclusión promovidos en el país hablan de adaptaciones curriculares de formación rápida de docentes (cuando existan). Frente a tanta presión para la inclusión, los profesores se sienten presionados y desmotivados a decir que no saben desenvolver dicho proceso. Al mostrarse temerosos a la inclusión, los profesores dejan explícitos no solo la falta de condiciones que están viviendo en las escuelas para que ese proceso acontezca, como también la falta de preparación para tal trabajo. [...] Es necesario saber sobre aquellos con quienes trabajamos. Saberes que van más allá de mi lectura sobre las condiciones de vida de mis estudiantes, o sea, necesito de conocimientos que me posibiliten trabajar desencadenando procesos de aprendizajes. Para esto, el saber sobre cómo los sujetos aprenden, sobre como conceptualizo el conocimiento, sobre como los sujetos sordos se comunican y sobre la propia Lengua Brasileña de Señales, sobre las particularidades de trabajar con personas portadoras de diversas deficiencias [...] es fundamental y condición mínima de trabajo" (LOPES, 2007, p. 27-28). 
realidad tiene mucho que ver, con construir espacios de encuentro positivos en los cuales explicamos, interpretamos o intervenimos en el mundo a partir de posiciones y disposiciones diferenciadas." ${ }^{17}$ En ese contexto, el educador, como precursor de la construcción de esos espacios de encuentro positivos, muchas veces se depara con desafíos que exigen un repensar constante de la práctica educativa, como enseñan Manica y Caliman:

\begin{abstract}
Assim, eximimos também o desejo do docente de vencer os desafios por meio de um planejamento diferenciado e de uma prática que exige mais desprendimento, organização do tempo e estudos extras. Propor uma aprendizagem ao aluno com deficiência que o faça refletir e "pensar" sobre sua identidade, considerando o "saber", a "bagagem" dos alunos, não é algo rotineiro nas salas de aula; exige o "querer" pedagógico desse docente comprometido com a diversidade. [...] Para que qualquer aluno, especialmente o aluno com deficiência, possa pensar e possa crescer no ambiente escolar, o docente deve propiciar espaços para propostas e atividades diferenciadas, em que os alunos vivam experiências multidisciplinares, raciocinem criticamente sobre os conteúdos, aprendam a solucionar problemas e, principalmente, acreditem que são agentes ativos no processo (MAMICA; CALIMAN, 2015, p. 70-71). ${ }^{18}$
\end{abstract}

Dada la importancia de la inclusión de las personas con deficiencia, y de extrema importancia la existencia de políticas públicas educativas, así como la creación e implementación de mecanismos pedagógicos orientados para la efectividad de la educación, de acuerdo con lo previsto en el artigo 206, inciso I de la constitución Federal de 1988, el cual indica la necesidad de que la enseñanza atienda al principio de la igualdad de condiciones, tanto de acceso, cuanto de permanencia. Silva reflexiona en consecuencia:

\footnotetext{
17 Traducción de las autoras del artículo. En el idioma original: "problematizar a realidade tem muito a ver, pois, com construir espaços de encontro positivos entre os quais explicamos, interpretamos ou intervimos no mundo a partir de posições e disposições diferenciadas."

18 Traducción de las autoras del artículo: "Así, liberamos también el deseo del docente de vencer los desafíos por medio de una planeación diferenciada y de una práctica que exige más desprendimiento, organización del tiempo y estudio adicionales. Proponer un aprendizaje al estudiante con deficiencia que lo haga reflexionar y 'pensar' sobre su identidad, considerando el 'saber', la 'experiencia' de los estudiantes no es algo común en las salas de clase; exige el 'querer' pedagógico de ese docente comprometido con la diversidad. [...] Para que cualquier estudiante, especialmente el estudiante con deficiencia, pueda pensar y pueda crecer en el ambiente escolar, el docente debe proveer espacios para propuestas y actividades diferenciadas, en que los estudiantes vivan experiencias multidisciplinares, raciocinen críticamente sobre los contenidos, aprendan a solucionar problemas y, principalmente, crean que son agentes activos en el proceso (MANICA; CALIMAN, 2015, p. 70-71).
} 


\begin{abstract}
A Constituição Federal é uma das mais avançadas do mundo em termo de legislação para inclusão social da pessoa com deficiência. A Convenção Internacional dos Direitos da Pessoa com Deficiência, recepcionada com status de norma constitucional, trouxe ainda mais outras dezenas de direitos fundamentais em benefício de trabalhadores desse grupo, como o direito fundamental ao trabalho, à acessibilidade, à adaptação razoável, à educação e qualificação profissional, e à autonomia e independência (SILVA, 2018, p. 17). ${ }^{19}$
\end{abstract}

Tal afirmación incluye un trato diferenciado para las personas con deficiencia (FOHRMANN; ANGÉLICA, 2015, p. 19). Tanto en los espacios universitarios, cuanto en los bancos escolares la inclusión de las personas consideradas normales y las anormales siguen siendo un desafío:

\begin{abstract}
Na escola e na universidade, "normais" e "anormais" estão sob suspeita, porém os "normais" não precisam estar, permanentemente, sendo normalizados. Ter uma pessoa com deficiência sentada ao lado de outras ditas normais não garante o lugar da normalidade, tampouco outras representações que rompam com a ideia do desvio, do problema e de alguém que necessita ser tolerado e tutelado. Ter aquele considerado com "necessidades educativas especiais" ao meu lado em sala de aula é ter próximo de mim alguém que me lembra a todo instante de que sou diferente dele, de que eu sou normal (LOPES, 2007, p. 29). ${ }^{20}$
\end{abstract}

Se tiene aquí un desafío enorme a ser enfrentado en la perspectiva de la responsabilidad asumida por el medio universitario para implementar las políticas públicas educativas destacadas por el ordenamiento jurídico. Al vislumbrarse las dificultades encontradas, tanto por los portadores de deficiencias, como por los no portadores, y también por los docentes que necesitan reconstruirse contantemente

19 Traducción de las autoras del artículo: "La Constitución Federal es una de las más avanzadas del mundo en términos de legislación para la inclusión social de las personas con discapacidad. La Convención Internacional sobre los Derechos de las Personas con Discapacidad, a la que se le ha otorgado estatus constitucional, ha traído aún más docenas de derechos fundamentales en beneficio de los trabajadores de este grupo, como el derecho fundamental al trabajo, la accesibilidad, la adaptación razonable, la educación y la calificación. autonomía e independência" (SILVA, 2018, p. $17)$.

20 Traducción de las autoras del artículo: "En la escuela y en la universidad, 'normales' y 'anormales' están sobre sospecha, sin embargo, los 'normales' no necesitan estar permanentemente, siendo normalizados. Tener una persona con deficiencia sentada al lado de otras consideradas normales no garantiza el lugar de la normalidad, tampoco otras representaciones que rompan con la idea del desvío, del problema y de alguien que necesita ser tolerado y protegido. Tener a aquel considerado con 'necesidades educativas especiales' a mi lado en sala de clase es tener cerca de mi a alguien que me recuerda a todo momento de que soy diferente de él, de que yo soy normal" (LOPES, 2007, p. 29). 
para aprender a construir una enseñanza heterogénea, se ve que los desafíos ocupan dimensiones mucho mayores a las del simple deber de incluir. Este desafío presenta profundas implicaciones para las Instituciones de Enseñanza Superior, haciendo con que sea un propósito urgente la construcción de condiciones factibles de acogida e inclusión para garantizar la dignidad de las personas con deficiencia:

\begin{abstract}
Adiar constantemente a construção de condições que facilitem os caminhos de dignidade só produz frustração e ansiedades. As propostas éticas que só dedicam atenção às formulações gerais de valores e/ou de direitos, ou, em outros termos, os fundamentalismos abstratos a partir dos quais se redigem incansavelmente novos textos de direitos e novas declarações de intenções (sem condições de factibilidade), estão cumprindo uma função alimentada pelos grandes interesses econômicos e políticos da nova ordem global: eliminar a radicalidade do político, como criação contínua e permanente de cidadania, e afastar o máximo possível os cidadãos dos espaços de decisão institucional (FLORES, 2009, p. 39). ${ }^{21}$
\end{abstract}

Frente a los diversos problemas revelados en la efectuación de la inclusión de persona con deficiencia en Instituciones de Enseñanza Superior inclusivas, frente al prisma de la responsabilidad por la enseñanza, surge la necesidad de adaptación de las metodologías pedagógicas de los docentes, así como de todo el currículo pedagógico, con el objetivo de acoger y efectivamente enseñar a las personas con deficiencia. Tornase así saludable el estudio y profundización de las problemáticas que se presentan para buscar soluciones mirando al presente y también hacia el futuro evitando, como menciona Flores:

[...] pensar nosso mundo a partir de perguntas ou problemáticas que, com o passar do tempo e dos acontecimentos, foram se desvanecendo ao terem sido formuladas para resolver problemas que hoje não temos ou os temos de outro modo, implica risco de assumir a passividade do que espera

\footnotetext{
21 Traducción de las autoras del artículo: "Posponer constantemente la construcción de condiciones que faciliten caminos dignos solo produce frustración y ansiedades. Las propuestas éticas que solo dedican atención a las formulaciones generales de valores y/o de derechos, o, en otros términos, los fundamentalismos abstractos a partir de los cuales se redactan incasablemente nuevos textos de derechos y nuevas declaraciones de intenciones (sin condiciones de factibilidad), están cumpliendo una función alimentada por los grandes intereses económicos y políticos de la nueva orden global: eliminar la radicalidad de lo político, como creación continua y permanente de ciudadanía, y alejar al máximo a los ciudadanos de los espacios de decisión institucional) (FLORES, 2009, p. 39)
} 
encontrar no passado as soluções para o presente (FLORES, 2009, P. 33). ${ }^{22}$

Es cierto que las Instituciones de Enseñanza Superior no pueden cerrarse para el otro, para la diferencia y la diversidad. La igualdad de acceso y permanencia a la enseñanza abriga a todos y todas sin distinción alguna. Para Meneses (2018, p. 5), "La limitación psíquica y/o intelectual no son suficientes para negar la autonomía, tampoco la capacidad, pues ambas son consideradas resultado de la dignidad". Así, con el objetivo de salvaguardar los derechos asegurados y el atendimiento al deber de responsabilidad que la enseñanza universitaria se propone, el tema de la inclusión debe ser reglamentado en actitudes proactivas, basadas en el respeto a la diferencia, que posibiliten el ingreso y la permanencia de las personas con deficiencia en la enseñanza superior del país.

Como el propósito de abordar el asunto del reconocimiento e inclusión de personas con deficiencia en espacios universitarios bajo la perspectiva humanista, nada mejor que volverse para un rol de derechos que Luiz Alberto Warat denomina como derechos de la alteridad. Entre ellos se encuentran: el derecho de no estar solo; el derecho al amor; a la autoestima; derecho de no sufrir ningún tipo de manipulación; de no sufrir discriminación y exclusión; de ser escuchado; el derecho a la propia velocidad (WARAT, 2010, p. 117). Esos derechos de alteridad, además de traer perspectivas inclusivas y de respeto, crean un ambiente de corresponsabilidad con el otro.

Es en este sentido paradoxal, complejo y desafiador que la inclusión de personas con deficiencia en los espacios sociales y universitarios se incluye. El tema requiere un ejercicio bastante profundo de alteridad para comprender lo diferente que envuelve la existencia de esas personas y reconocer el otro en su dignidad y autoestima, forjando un nuevo espacio entre-nosotros, más humano. Para esto, se hace necesario el reconocimiento de esas personas que transita tanto por el

22 Traducción de las autoras del artículo: "Pensar nuestro mundo a partir de preguntas o problemáticas que, con el pasar del tiempo y de los acontecimientos, fueron desvaneciéndose al haber sido formuladas para resolver problemas que hoy no tenemos o los tenemos de otro modo, implica el riesgo de asumir la pasividad del que espera encontrar en el pasado las soluciones para el presente" (FLORES, 2009, p. 33). 
ambiente del Estado de Derecho, a través de la creación de normas jurídicas inclusivas, cuanto por el reconocimiento social y consecuente inclusión de las personas con deficiencia, respetando sus diferencias.

\section{CONSIDERACIONES FINALES}

La inclusión de personas que no se ajustan a la cama de Procusto en los espacios sociales requiere un proceso complejo que incluye un salir de nosotros mismos para ver el otro, comprender sus diferencias y la diversidad de todo lo que representa la existencia humana. Por consiguiente, el reconocimiento de los individuos en el medio social representa una complejidad de inter-relaciones que se desenvuelven de las más diversas formas. La aceptación de los diferentes se depara con barreras y criterios pre-concebidos, semejantes a la cama de Procusto, que afectan directamente la perspectiva inclusiva, como ocurre con las personas con diferencia en espacios universitarios, lanzando grandes desafíos en los procesos de inclusión social.

La inclusión de personas con deficiencias en la enseñanza superior brasileña se depara con la perspectiva hegemónica de segregación de todo y todos los que son diferentes, alejando, muchas veces, la posibilidad de inclusión de personas con deficiencia en la sociedad y en la academia. En este contexto, es necesario que acontezcan cambios de paradigmas que permitan la efectividad de políticas públicas de inclusión, permitiendo a todos y todas, sin distinción, acceso a una educación superior de calidad, sin preconceptos, que supere las ataduras jurídicas y entre en la zafra de la alteridad y de la responsabilidad.

El asunto de la efectividad de la inclusión en discusión es objeto de varios dilemas, pues a pesar de haber una serie de reglas que incluyen a las personas con deficiencia, ellas por sí solas no son suficientes para garantizar la implementación de la inclusión, es necesaria una profunda transformación en las relaciones sociales. Además de la voluntad política y jurídica de implementar la inclusión, el cambio de posicionamiento, de entendimiento y de relación con el otro 
son de fundamental importancia para el acceso y permanencia de las personas en la enseñanza superior.

Considerando que las leyes y las políticas deben acompañar la evolución social de modo que proporcionen un mayor acompañamiento de las cuestiones relacionadas a la inclusión, es importante que ocurra la adecuada previsión y planeación de acciones en perspectiva positiva, garantizando que el Estado cumpla su papel. Se percibe que la inclusión puede ser perfeccionada de varias formas, desde el cambio en la forma de pensar y enseñar, superando la forma puramente homogénea y cambios en algunas metodologías tradicionales hacia una mirada heterogénea donde se ve al sujeto con sus particularidades y capacidad de autonomía, hasta la modificación en el modo de amparar y reconocer.

Para que una universidad sea verdaderamente inclusiva es necesaria la participación de toda la comunidad escolar, así como del poder público, teniendo en cuenta que incluir es mucho más que recibir las personas con deficiencia en una estructura institucional adecuada, incluir, en el contexto de las instituciones de enseñanza, es posibilitar que todos los estudiantes tengan las mismas posibilidades de aprender. Todos deben tener acceso a una educación de calidad que considere sus condiciones físicas y psíquicas, a una educación humanizada, al promover la inclusión, y no la integración, las Universidades proporcionan a la comunidad en la que está inserida la amplia propagación de valores éticos y respeto a los derechos humanos y, al mismo tiempo, aleja a las personas con deficiencia de la cama de Procusto.

\section{REFERÊNCIAS}

BRASIL. Decreto 6.949, de 25 de agosto de 2009. Promulga a Convenção Internacional sobre os Direitos das Pessoas com Deficiência e seu Protocolo Facultativo, assinados em Nova York, em 30 de março de 2007. Disponible en: <https://www.planalto.gov.br/ccivil_03/_ato2007-2010/2009/decreto/d6949.htm>. Acceso en: 26 jul. 2019.

Lei 10.098, de 19 de dezembro de 2000. Estabelece normas gerais e critérios básicos para a promoção da acessibilidade das pessoas portadoras de 
deficiência ou com mobilidade reduzida, e dá outras providências. Disponible en: $<$ https://www.planalto.gov.br/ccivil_03/leis/110098.htm>. Acceso en: 26 jul. 2019.

. Lei 10.436, de 24 de abril de 2002. Dispõe sobre a Língua Brasileira de Sinais - Libras e dá outras providências. Disponible en: <https://www.planalto.gov.br/ccivil_03/leis/2002//10436.htm>. Acceso en: 26 jul. 2019.

. Lei 12.764, de 27 de dezembro de 2012. Institui a Política Nacional de Proteção dos Direitos da Pessoa com Transtorno do Espectro Autista; e altera o § 30 do art. 98 da Lei no 8.112, de 11 de dezembro de 1990. Disponible en: <https://www.planalto.gov.br/ccivil_03/_ato2011-2014/2012/lei/112764.htm>. Acceso en: 26 jul. 2019.

Lei 13.146, de 6 de Julho de 2015. Institui a Lei Brasileira de Inclusão da Pessoa com Deficiência (Estatuto da Pessoa com Deficiência). Disponible en: <https://www.planalto.gov.br/ccivil_03/_ato2015-2018/2015/lei/13146.htm>. Acceso en: 26 jul. 2019.

MENEZES, Joyceane Bezerra de. A capacidade jurídica pela Convenção sobre os Direitos da Pessoa com Deficiência e a insuficiência dos critérios do status, do resultado da conduta e da funcionalidade. Revista Pensar: Fortaleza, v. 23, n. 2, p. 1-13, abr./jun. $2018 . \quad$ Disponible en <https://periodicos.unifor.br/rpen/article/view/7990>. Acceso en: 10 ago. 2019.

CARBONARI, Paulo Cesar. Educação em Direitos Humanos: por uma nova pedagogia. In: VIOLA, Solon Eduardo Annes; ALBUQUERQUE, Marina Z. de [Orgs.]. Fundamentos para educação em direitos humanos. São Leopoldo: Sinodal/EST, 2011.

CASTELLS, Manuel. O Poder da Identidade. Tradução: Klauss Brandini Gerhardt, São Paulo, Paz e Terra, 2010.

DECLARAÇÃO DE SALAMANCA. Sobre Princípios, Políticas e Práticas na Área das Necessidades Educativas Especiais. Ministério da Educação e Cultura. Disponible en : http://portal.mec.gov.br/seesp/arquivos/pdf/salamanca.pdf. Acceso en: 26 jul. 2019.

FLORES, Joaquín Herrera. Teoria Crítica dos Direitos Humanos: Os Direitos Humanos como Produtos Culturais. Rio de Janeiro: Editora Lumen Juris, 2009.

FOHRMANN, Ana Paula Barbosa; ANGÉLICA, Thiago da Costa Sá. Crianças com deficiência e o acesso à educação fundamental no Brasil: inclusão ou integração? Uma análise a partir do direito constitucional. Revista Pensar, Fortaleza, v. 19, n. 1, p. 9-34, jan./abr. 2014. Disponible en <https://periodicos.unifor.br/rpen/article/view/2651/pdf_1>. Acceso en: 10 ago. 2019. 
HAHN, Noli Bernardo; ANGELIN, Rosângela. Contribuição dos Movimentos Feministas para a cultura dos Direitos Humanos mediante a perspectiva da racionalidade descentrada. In: SANTOS, André Copetti; HAHN, Noli Bernardo; ANGELIN, Rosângela [Coord.]. Policromias da Diferença: Inovações sobre Pluralismo, Direito e Interculturalidade. Curitiba: Juruá, 2015. p. 65-78.

HALL, Stuart. Quem precisa da Identidade? In: SILVA, Tomaz Tadeu da. [Org.]. Identidade e Diferença: a perspectiva dos Estudos Culturais. Petrópolis: Vozes, 2013. p. 73-133.

LOPES, Maura Corcini. Inclusão escolar currículo, diferença e identidade. In: LOPES, Maura Corcini [Org.]. In/exclusão: nas tramas da escola. Canoas: Ed. ULBRA, 2007, pp. 11-33.

MALEUS, Marcelino; THAINES, Aletéia Hummes. Mediação Waratiana: Uma aposta na alteridade. Cátedra Luis Alberto Warat [Recurso eletrônico on-line] organização CONPEDI/UFS; Coordenadores: Leonel Severo Rocha, Cecilia Caballero Lois, Marcelino Meleu - Florianópolis: CONPEDI, 2015. Disponible en: $<$ https://www.conpedi.org.br/publicacoes/c178h0tg/2y368zo8/mwhGNpTvy7tq3Ezd.p df> . Acceso en: 27 jul. 2019.

MANICA, Loni Elisete; CALIMAN, Geraldo. A educação profissional para pessoas com deficiência: um novo jeito de ser docente. Brasília: Liber Livro, 2015.

OLIVEIRA JÚNIOR, José Alcebíades de. Teoria Crítica e Direitos de Alteridade na obra de Warat. Teoria Crítica do Direito - CONPEDI. 2014. Disponible en: <http://publicadireito.com.br/publicacao/ufsc/livro.php?gt=204>. Accesso en: 27 jul. 2019.

PLAISANCE, Eric. Da educação especial à educação inclusiva: esclarecendo as palavras para definir as práticas. Revista Educação. Porto alegre, v. 38, n. 2, p. 230-238, maio-ago. 2015.

SIDEKUM, Antônio. Alteridade e interculturalidade. In: SIDEKUM, Antônio. [Org.] Alteridade e multiculturalismo. Coleção Ciências Sociais. ljuí: ed. Unijuí, 2003.

SILVA, Luciana Aboim Machado Gonçalves da. A inclusão da pessoa com deficiência no mercado do trabalho no Brasil: em busca da efetividade das agências do sistema nacional de emprego. Revista Jurídica - UNICURITIBA. vol. 04, $\mathrm{n}^{\circ}$. 53, Curitiba, 2018.2 pp. 306-325. Disponible en: <http://revista.unicuritiba.edu.br/index.php/RevJur/article/view/3221/371371737>. Acceso en: 20 ago. 2019.

SILVA, Tomaz Tadeu da. A produção social da identidade e da diferença. In: SILVA, Tomaz Tadeu da. [Org.] Identidade e Diferença: a perspectiva dos estudos culturais. 13. Ed. Petrópolis, RJ: Vozes, 2013. p. 73-102. 
TAYLOR, Charles. Multiculturalismo. Lisboa: Instituto Piaget, 1994.

WARAT, Luis Alberto. A rua grita Dionísio! Direitos humanos da alteridade, surrealismo e cartografia. Tradução e organização de Vivian Alves de Assis, Júlio Cesar Marcellino Jr. e Alexandre Morais da Rosa. Rio de Janeiro: Lumen Juris, 2010.

WARAT, Luis Alberto. Por quien Cantan Las Sirenas. Chapecó: UNOESC/CPGD, 1996.

WARAT, Luis Alberto. Surfando na pororoca: ofício do mediador. Florianópolis: Fundação B/oiteux, 2004.

WOODWARD, Kathryn. Identidade e diferença: uma introdução teórica e conceitual. In: SILVA, Tomaz Tadeu da. [Org.] Identidade e Diferença: a perspectiva dos estudos culturais. 13. ed. Petrópolis, RJ: Vozes, 2013, p. 7-72. 